Review article

\title{
Quinary prevention in diabetes care: Need for multidisciplinary approach
}

\author{
D. Dutta ${ }^{\mathrm{a}, *}$, V. Arora ${ }^{\mathrm{b}}$, A. Dhingra ${ }^{\mathrm{c}}$, A.K. Das ${ }^{\mathrm{d}}$, Md Fariduddin ${ }^{\mathrm{e}}, \mathrm{K}$. Shaikh $^{\mathrm{f}}$, G. Priya $^{\mathrm{g}}$, P. Shah ${ }^{\mathrm{h}}$, \\ A.A. Rehim ${ }^{i}$, M. John ${ }^{j}$, S. Shaikh ${ }^{\mathrm{k}}$, A. Orabi ${ }^{1}$, M.R. Saraswati ${ }^{\mathrm{m}}$, S. Selim ${ }^{\mathrm{n}}$, M.P. Baruah ${ }^{\circ}$, K. \\ K. Gangopadhyay ${ }^{p}$, Y.A. Langi ${ }^{q}$, T. Nair ${ }^{r}$, D. Dhanwal ${ }^{\text {s }}$, S.D. Thapa ${ }^{t}$, V. Deshmukh ${ }^{\mathrm{u}}$, \\ H. Khalfan ${ }^{\mathrm{v}}$, R. Maskey ${ }^{\mathrm{w}}$, S. Das ${ }^{\mathrm{x}}$, A. Dasgupta ${ }^{\mathrm{y}}$, A. Bajaj $^{\mathrm{z}}$, N. Pandey ${ }^{\mathrm{aa}}$, A. AlAni $^{\mathrm{bb}}$, \\ M. Moosa ${ }^{c c}$, S. Kalra ${ }^{\text {dd }}$
}

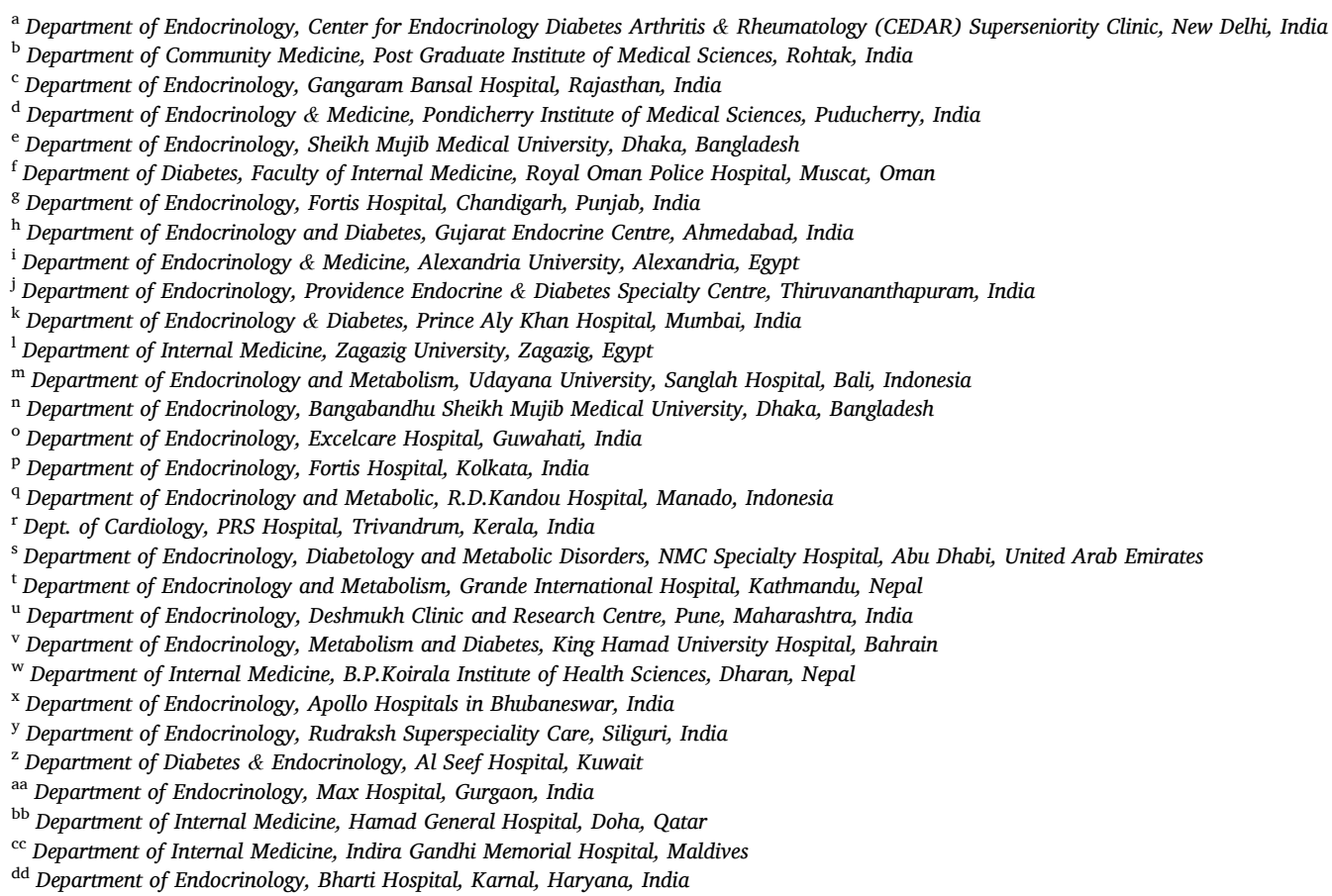

\section{A R T I C L E I N F O}

\section{Keywords:}

Type 2 diabetes mellitus

Quinary prevention

de-hearsay

e-hearsay

Misinformation

\begin{abstract}
A B S T R A C T
Problem considered: Type 2 diabetes mellitus (T2DM) is a global pandemic with increasing prevalence worldwide. Hearsay, or reported speech, is an important contributor to diabetes care related behavior and may influence the outcomes of diabetes treatment. An emerging concept in preventive medicine is Quinary prevention which aims at preventing health-related hearsay or misinformation.

Methods: A group of international clinical experts comprising endocrinologists, diabetologists, cardiologists and community medicine specialists gathered in India and discussed ways to restrain the menace of de-hearsay in diabetes care.
\end{abstract}

\footnotetext{
* Corresponding author. Department of Endocrinology, Center for Endocrinology Diabetes Arthritis \& Rheumatology (CEDAR) Superseniority Clinic, New Delhi, India.

E-mail address: deepdutta2000@yahoo.com (D. Dutta).
} 
Results: Based on the discussion, the expert panel endorsed the term 'quinary prevention,' which is a mode of preventing the spread of false health information. The panel also outlined several means through which the physician community can prevent the spread of misinformation.

Conclusions: Considering the increasing use of technology by the general population, treating health care professionals should keep updating with the newer research evidences in their fields and disseminate authentic knowledge on diabetes care on social media, print media as well as other mass media, thereby diabetes promoting self-management, as well as public health.

\section{Introduction}

The global incidence of diabetes mellitus (DM) has quadrupled over the last two decades; the number of affected individuals has been increasing at an alarmingly rapid pace. ${ }^{1}$ According to the 2019 International Diabetes Federation (IDF) report, about 463 million people were living with diabetes; this figure is projected to increase by $51 \%$ and reach nearly 578 million by 2030 and 700 million by $2045 .^{2}$ These alarming projections call for the implementation of innovative strategies for the prevention and treatment of DM.

Various factors have been implicated for the increasing prevalence of $\mathrm{DM}$, including the increase in the aging population, changing lifestyles, obesity, socioeconomic factors, and urbanization. ${ }^{3}$ Diabetes mellitus is a complex, heterogeneous metabolic condition that results from an interaction between the genetic predisposition of an individual and environmental triggers. ${ }^{4}$

Misinformation is one of the major challenges in the context of global health. Misinformation on the prevention and management of DM, as well as that related to healthcare-seeking behavior, has become an inevitable challenge for treating physicians. Hearsay, or reported speech, is an important contributor to diabetes care related behavior and may influence the outcomes of diabetes treatment. Further, misinformation obtained from the Internet through social and other electronic media has increased the burden of health care professionals in tackling T2DM. De-hearsay plays a significant role in determining healthcareseeking behavior and healthcare acceptance in people with diabetes. ${ }^{5}$

\section{Methodology}

During a two-day clinical expert group meeting on February 8th and 9th 2020 in New Delhi, the experts discussed the issue of misinformation pertaining to diabetes care and provided individual insights based on experience for the management of DM. The focus was on the emerging new concept of quinary prevention and its utility in diabetic care. The experts then formulated key opinions based on scientific evidence and clinical judgment. Clinical perspectives for quinary prevention are summarized in this article.

\subsection{Digital revolution and impact on health care}

The recent years have witnessed great strides in the use of digital technology and social media. The number of social network users in India stood at 326.1 million in 2018 and is projected to reach 448 million by $2023 .^{5}$ Technological advancement facilitates the rapid transmission of information, thereby enhancing the efficacy of healthcare systems. However, misinformation and hearsay disseminated through these same platforms may adversely affect the health and well-being of patients. The prevalence of de-hearsay or e-hearsay has been increasing in the past few years and has hindered the achievement of good healthcare. ${ }^{6}$ Diabetes e-hearsay refers to diabetes-related misinformation disseminated via messages on cellphones or misinformation uploaded on social media sites. ${ }^{5}$ Sources of de-hearsay include the traditional media, educational/healthcare websites, cellphone-based forwarded messages, social media, and direct consumer marketing. More often, inaccurate messages are usually spread fast on social media platforms, leading to the consumption of nonevidence-based medications including home remedies as well as non-prescription alternate medications. ${ }^{7}$ False information pertaining to etiology, pathogenesis, screening, diagnosis, classification, diet, exercise, oral drugs, insulin, self-monitoring of blood glucose, and modern diabetes care is often propagated. The experts discussed and opined on the spread diabetes electronic hearsay (De-hearsay), summarized in Table 1.

The experts suggested that the healthcare professionals should take practical measures to give accurate information to patients and should also direct patients to use reliable electronic health information (usually sites hosted by professional bodies or those curated by experts) or holistic management approach websites. ${ }^{7}$ To curb the menace of hearsay (de-hearsay and e-hearsay) in diabetes care, strict regulations and policies should be in place to discourage and prevent the spread of misinformation. Quinary prevention is a new term that has been coined to describe the prevention of hearsay in healthcare.

\subsection{Spectrum of various levels of prevention}

Importance of preventive medicine has widespread with health care professionals and the general population. Preventive medicine aims at arresting the progress of the disease by intercepting or opposing the "cause" of disease. ${ }^{6}$

Preventive care is practiced at various levels, which are conventionally listed as primary, secondary and tertiary (Table 2). Emerging evidence on preventive medicine also paved the path to primordial and quaternary prevention. ${ }^{8}$

\section{Need of a novel preventive measure in the digital era}

Prevention of spread or effects of wrong health and/or health measures related information is important in today's digital savvy environment, which allows rapid and wide dispersal of (mis) information.

Table 1

Common misinformation about diabetes and its management.

\begin{tabular}{|c|c|}
\hline \multicolumn{2}{|c|}{ Examples of diabetes-electronic hearsay (De-hearsay) } \\
\hline Etiology & $\begin{array}{l}\text { Diabetes occurs because of eating too many mangoes \& } \\
\text { bananas }\end{array}$ \\
\hline Pathogenesis & Diabetes cannot occur if one does not have a family history \\
\hline Screening & Repeated testing for diabetes causes diabetes \\
\hline Diagnosis & $\begin{array}{l}\text { Diagnosis of diabetes cannot be confirmed until sugar is } \\
\text { detected in the urine }\end{array}$ \\
\hline Classification & $\begin{array}{l}\text { 1. There are two types of diabetes: urine sugar and blood sugar } \\
\text { 2. Type } 2 \text { diabetes is less dangerous than type } 1 \text { diabetes } \\
\text { 3. Diabetes that develops during pregnancy disappears } \\
\text { completely after delivery and no further care is needed }\end{array}$ \\
\hline Course & $\begin{array}{l}\text { Diabetes is temporary and will disappear if one avoids eating } \\
\text { sugar }\end{array}$ \\
\hline Diet & Bitter gourd and coriander juice cures diabetes \\
\hline Exercise & Five minutes of yoga is better than $50 \mathrm{~min}$ of aerobics \\
\hline Oral drugs & Oral drugs are harmful and can cause multi organ damage \\
\hline Insulin & $\begin{array}{l}\text { 1. Starting Insulin is the end stage in diabetes } \\
\text { 2. Insulin is harmful and people become addicted to it }\end{array}$ \\
\hline Monitoring & $\begin{array}{l}\text { 1. If readings are normal, kidney function and cholesterol } \\
\text { levels need not be checked }\end{array}$ \\
\hline $\begin{array}{l}\text { Modern diabetes } \\
\text { care }\end{array}$ & Modern medications have no side-effects \\
\hline
\end{tabular}


Table 2

Levels of Prevention in health care.

\begin{tabular}{|c|c|c|}
\hline $\begin{array}{l}\text { Level of } \\
\text { prevention }\end{array}$ & Definitions & Mode of Intervention \\
\hline $\begin{array}{l}\text { Primordial } \\
\text { Prevention }\end{array}$ & $\begin{array}{l}\text { Prevention of emergence or } \\
\text { development of risk factors. }\end{array}$ & $\begin{array}{l}\text { Health education } \\
\text { Health Promotion }\end{array}$ \\
\hline $\begin{array}{l}\text { Primary } \\
\text { Prevention }\end{array}$ & $\begin{array}{l}\text { Prevention of disease when risk } \\
\text { factor is present }\end{array}$ & $\begin{array}{l}\text { Lifestyle modification } \\
\text { Immunization }\end{array}$ \\
\hline $\begin{array}{l}\text { Secondary } \\
\text { Prevention }\end{array}$ & $\begin{array}{l}\text { Prevention of complication of } \\
\text { disease from occurring }\end{array}$ & $\begin{array}{l}\text { Early diagnosis } \\
\text { Prompt, optimized and } \\
\text { sustained care }\end{array}$ \\
\hline $\begin{array}{l}\text { Tertiary } \\
\text { Prevention }\end{array}$ & Prevention of disability or death & $\begin{array}{l}\text { Rehabilitation } \\
\text { Disability prevention }\end{array}$ \\
\hline $\begin{array}{l}\text { Quaternary } \\
\text { Prevention }\end{array}$ & $\begin{array}{l}\text { Prevention of over diagnosis and } \\
\text { treatment }\end{array}$ & $\begin{array}{l}\text { Rehabilitation } \\
\text { Disability prevention }\end{array}$ \\
\hline
\end{tabular}

For accurate scientific communication of this idea, an appropriate term needs to be coined, along with precise conceptualization and definition. This concept and definition should be applicable to all health care settings, and all health care professionals.

The new scientific term 'quinary prevention' was coined by Kalra et al. and was created to describe the fifth level of prevention. The word 'quinary' is derived from the Latin word 'quinarius' and describes the fifth object in a series, and hence quinary prevention describes the fifth level of prevention. Quinary prevention overlaps and includes all levels of prevention (primary, secondary, tertiary, and quaternary, see Fig. 1). Effective quinary prevention can achieve effective primary, secondary, or tertiary prevention. ${ }^{5}$ Primary prevention aims at preventing specific diseases and includes primordial prevention, while quaternary prevention is used to identify patients at risk of over-medicalization and to protect them from new medical invasions and suggest ethically acceptable interventions. ${ }^{9}$ All forms of prevention aim to meet the various challenges of global health, in a proactive manner.

\subsection{Quinary prevention- definition and conceptualization}

A comprehensive definition of quinary prevention: ${ }^{6}$

"Policies, conditions, actions and measures, that inhibit the emergence and establishment of processes and factors, that increase the risk of communication of inappropriate information, related to health, disease prevention or management, and/or that minimize the risks of communicating any such inappropriate information, hence minimizing the effect of such misinformation on the progression or development of disease at any stage during its natural history".

A simpler definition of quinary prevention is as follows: ${ }^{6}$
"Means of preventing health-related hearsay or misinformation, or its ill effects on the health of individuals." Quinary prevention encompasses all levels of prevention and is mandatory for. effective primary, secondary or tertiary prevention.

\subsection{Quinary prevention in diabetes care}

In the era of rapid and wide dispersal of health-related misinformation, it is necessary to control this misinformation in the initial stage itself. Initial diabetes spread should be handled by primary intervention measures, including healthy lifestyle, changing dietary/culinary patterns, physical activity, and stress management. ${ }^{10}$ Further, better availability of healthcare facilitates secondary and tertiary prevention of T2DM. Quinary prevention aids in the avoidance of misinformation and hearsay, thereby improving efforts to control diabetes. A study by Leong et al. reported that $32.4 \%$ of YouTube videos on T2DM were misleading. They further reported that misleading videos were more popular than useful videos (median, 233 views/day; interquartile range (IQR), 26 to 523; vs. 8.3 views/day; IQR, 0.4 to 134.6 ; $<<0.01) .{ }^{11}$ De-hearsay can be curbed by collective, concerted efforts by healthcare providers, patients, and governments. Quinary prevention is a multilayered responsibility of healthcare professionals, professional bodies, and governments. By constantly updating themselves, healthcare professionals should disseminate accurate information and spread health literacy. Healthcare providers can disseminate knowledge on self-management and self-care of DM on social media. This is because HCPs cannot be available $24 \times 7$ $\times 365$ to answer all of questions posed by people with diabetes, By leveraging the power of social media platforms, HCPs can actively participate on the overall care of diabetes by ensuring authentic information is accessed by people with diabetes. ${ }^{12}$ This aspect was clearly demonstrated in a web-based and in-clinic surveys by Nelakurthi et al., who reported that regular use of social media by people with DM significantly improved self-reported adherence to lifestyle recommendations. ${ }^{13}$ Another study by Abedin et al. on Facebook groups identified 16 eligible diabetes foot care-related Facebook groups with a total of 103 eligible posts. Of the total 103 timeline posts, $45.6 \%$ were considered useful; the commonly mentioned diabetes foot care practice was 'checking feet daily'. ${ }^{14}$ This study supports the use of Facebook as a useful platform for sharing information on DM care. The utility of this platform can be improved even more if healthcare providers disseminate useful, authentic information on diabetes care. Similar findings were reported in a study of 56 children and adolescents with type 1 diabetes by Petrovski et al., who found that regular use of Facebook and Skype allowed people to improve knowledge and interact in their daily insulin

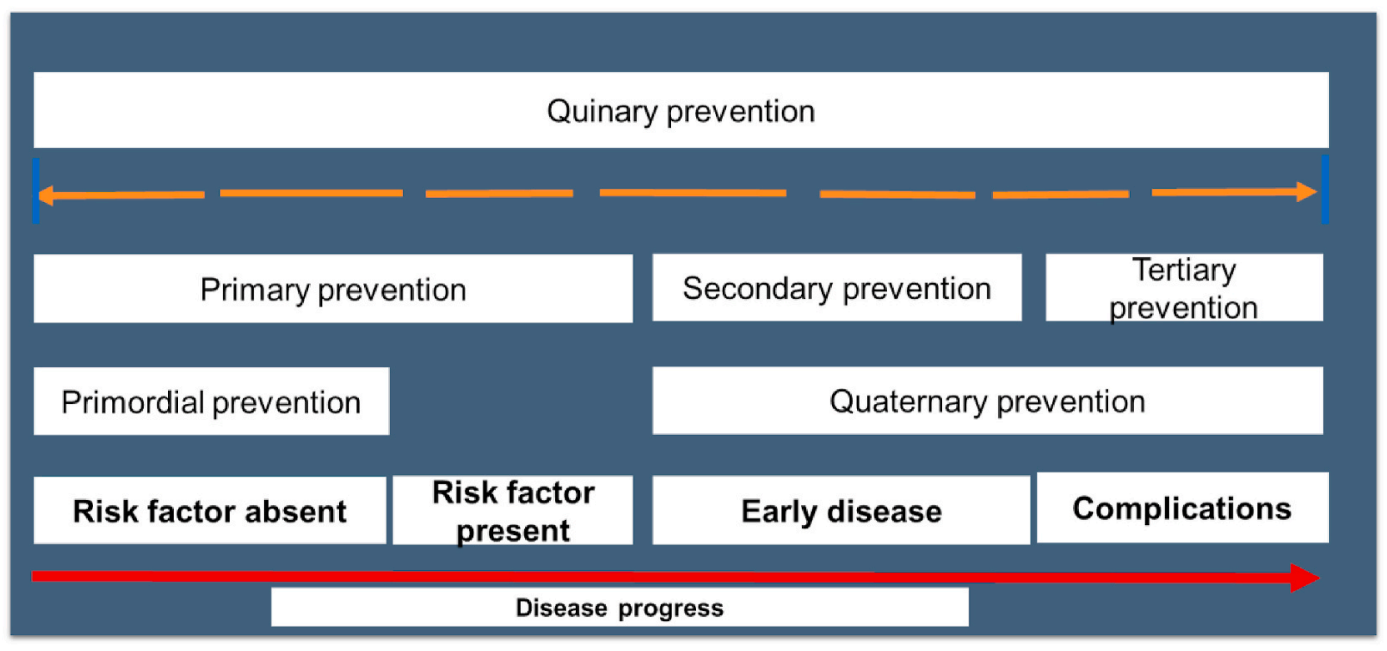

Fig. 1. Concept of quinary prevention. 
adjustments. This activity also ensured that persons with T1D were able to cope in a better manner. ${ }^{15}$

Healthcare providers may also be involved in decision-making to bring about effective systemic changes. Further, professional bodies should host user-friendly patient information websites curated by therapeutic experts. ${ }^{5,6}$ Further, the government should discourage and prevent the spread of misinformation regarding healthcare. This rule should be applicable to both social media and print media. While doctors lead the way, it is important to realize that for social changes to occur, there must be a multipronged approach.

Diabetic e-hearsay (De-hearsay) can be tackled in multiple ways by health care professionals. It should be a part of their clinical practice, to improve public health. ${ }^{5}$ It can be managed through outreach programs, by promoting scientific information related to diabetes, including dispelling myths about diabetes (Table 3). Further, healthcare providers can engage in health advocacy programs-including health talk and blogs posts. ${ }^{5}$

\subsection{Quinary prevention and pharmacotherapy for diabetes care}

Sources of de-hearsay include educational and healthcare providerdriven (unqualified health care providers and practitioners of complementary health systems) websites, pharmaceutical driven (direct to consumer marketing, unproven drugs), social media, traditional media, and telephone-based messages. ${ }^{5}$ The experts opined that misleading messages are often spread rapidly, which compel readers to promote consumption of non-evidence-based medications. In fact, traditional herbal medications are often displayed as pure and harmless, although they may contain hazardous heavy metals and unknown chemicals and have not undergone rigorous scrutiny in well-conducted trials. ${ }^{16}$

\subsection{Responsibilities at various levels to minimize misinformation}

Policy makers, healthcare professionals and public should act together in a responsible manner to minimize misinformation. Specific details regarding what can be done by these three pillars of our society have been elaborated in the table.

\begin{tabular}{|c|c|}
\hline $\begin{array}{l}\text { Level of } \\
\text { responsibility }\end{array}$ & Action points \\
\hline Policy makers & $\begin{array}{l}\text { - Legislation to discourage and prevent spread of 'wrong' } \\
\text { health related information via social media (including } \\
\text { Facebook, Twitter and WhatsApp) and mass media (print } \\
\text { radio television. } \\
\text { - Administrators of social platforms should curate, and } \\
\text { censor, health-related posts which are false, and may harm } \\
\text { public or individual health. }\end{array}$ \\
\hline $\begin{array}{l}\text { Health care } \\
\text { professionals }\end{array}$ & $\begin{array}{l}\text { - Aim to spread health literacy across civil society. } \\
\text { Constantly updating themselves in their chosen discipline, } \\
\text { the science of information dissemination. } \\
\text { - Report the misinformation to appropriate authority to take } \\
\text { necessary actions. } \\
\text { - Refraining from voicing or airing comments about subjects } \\
\text { with which they are not familiar or are not qualified to } \\
\text { speak on. } \\
\text { - Information campaigns to the public for awareness of how } \\
\text { to differentiate between 'true' advice and 'e-hearsay', and } \\
\text { to refrain from spreading false propaganda. }\end{array}$ \\
\hline Public & $\begin{array}{l}\text { - Not believing every forwarded messages and information's } \\
\text { received the social media } \\
\text { - Consulting the health care professional for clarifying the } \\
\text { information related to the health and information } \\
\text { received. }\end{array}$ \\
\hline
\end{tabular}

\section{Conclusion}

Quinary prevention plays an important role in preventing the propagation of misinformation or diabetes-related hearsay. Health care professionals should actively engage in limiting the de-hearsay menace,
Table 3

Clinical perspectives on Myths and Truths in Diabetes Care.

\begin{tabular}{|c|c|}
\hline Myth & Truth \\
\hline $\begin{array}{l}\text { The diagnostic cut offs for diabetes have } \\
\text { recently been lowered to suit vested } \\
\text { interests }\end{array}$ & $\begin{array}{l}\text { The diagnostic criteria for diabetes have } \\
\text { been the same for the past } 2 \text { decades and } \\
\text { are based on established evidence for the } \\
\text { levels of blood glucose above which the } \\
\text { risk of complications begins to increase }\end{array}$ \\
\hline Medications for diabetes harm the body & $\begin{array}{l}\text { Uncontrolled diabetes harms the body; } \\
\text { medications not only bring symptomatic } \\
\text { relief; they also reduce the risk of diabetes } \\
\text { complications }\end{array}$ \\
\hline Insulin causes kidney failure & Insulin does not harm the kidney \\
\hline Cholesterol -lowering drugs are harmful & $\begin{array}{l}\text { Statins lower risk of atherosclerotic } \\
\text { cardiovascular diseases }\end{array}$ \\
\hline $\begin{array}{l}\text { Jaggery and honey don't increase } \\
\text { glucose levels }\end{array}$ & $\begin{array}{l}\text { Jaggery and honey are as bad as sugar for } \\
\text { persons with diabetes }\end{array}$ \\
\hline $\begin{array}{l}\text { Person with diabetes cannot exercise } \\
\text { safely }\end{array}$ & $\begin{array}{l}\text { Exercise is an essential part of diabetes } \\
\text { therapy }\end{array}$ \\
\hline
\end{tabular}

as part of routine clinical practice. Further, as social media platforms expand to reach more people, healthcare providers should use these platforms to disseminate informative and authentic knowledge on diabetes care.

\section{Summary}

- The expert panel put forward clinical practice-based opinion regarding quinary prevention in diabetes care.

- This will serve as a reference for clinicians treating diabetes and cardiovascular disease on how to tackle the de-hearsay menace.

\section{Disclosures}

All authors had full access to the articles reviewed in this manuscript, have read and reviewed the final draft of this manuscript and take complete responsibility for the integrity and accuracy of this manuscript. Before submission to the journal Sanofi was given the opportunity to review the manuscript. However, the authors remain responsible for all content and editorial decisions. The content published herein solely represents the views and opinions of the authors and does not represent the views or opinion of Sanofi and/or its affiliates.

\section{Funding}

This initiative was supported by Sanofi India. Medical writing related charges were paid for by Sanofi India. The authors received no honoraria from Sanofi directly or indirectly related to the development of this publication.

\section{Authorship}

All named authors meet the International Committee of Medical Journal Editors (ICMJE) criteria for authorship for this article, take responsibility for the integrity of the work as a whole, and have given their approval for this version to be published.

\section{Declaration of competing interest}

The authors received honorarium from Sanofi for participating in the two-day advisory board meeting.

\section{Acknowledgments}

We would like to thank Dr Rajshri Mallabadi from BioQuest Solutions Pvt. Ltd., Bangalore, for providing medical writing and editorial support in the preparation of this manuscript paid for by Sanofi India. 


\section{References}

1 Bashier A, Bin Hussain A, Abdelgadir E, Alawadi F, Sabbour H, Chilton R. Consensus recommendations for management of patients with type 2 diabetes mellitus and cardiovascular diseases. Diabetol Metab Syndrome. 2019;11:80.

2 IDF DIABETES ATLAS. ninth ed. https://www.diabetesatlas.org/en/resources/; 2019 3 Thibault V, Bélanger M, LeBlanc E, Babin L, Halpine S, Greene B. Factors that could explain the increasing prevalence of type 2 diabetes among adults in a Canadian province: a critical review and analysis. Diabetol Metab Syndrome. 2016;8:71.

4 Javeed N, Matveyenko AV. Circadian etiology of type 2 diabetes mellitus. Physiology. 2018;33:138-150.

5 Kalra S, Balachandran K. De-hearsay (diabetes e-hearsay). J Pakistan Med Assoc. 2017;67:1293-1295.

6 Diwanji Sanika. Number of social network users India. https://www.statista.com/st atistics/278407/number-of-social-network-users-in-india/; 2015-2023. Accessed May 21, 2020.

7 Kalra S, Kumar A. Quinary prevention: defined and conceptualized. J Pakistan Med Assoc. 2019;69:1765-1766.

8 Kalra S, Balachandran K. Technosocial competence in diabetology. Indian J Endocr Metab. 2017;21:489.
9 Park K. Park Textbook of Preventive and Social Medicine. twenty fifth ed. 2019.

10 Pandve HT. Quaternary prevention: need of the hour. J Fam Med Prim Care. 2014;3: 309-310.

11 Asif M. The prevention and control the type-2 diabetes by changing lifestyle and dietary pattern. $J$ Educ Health Promot. 2014;3:1

12 Leong AY, Sanghera R, Jhajj J, Desai N, Jammu BS, Makowsky MJ. Is YouTube useful as a source of health information for adults with type 2 diabetes? A south Asian perspective. Can J Diabetes. 2018;42, 395-03.e4.

13 McMahon LK. Power and pitfalls of social media in diabetes care. Diabetes Spectr. 2013;26:232-235.

14 Nelakurthi AR, Pinto AM, Cook CB, et al. Should patients with diabetes be encouraged to integrate social media into their care plan? Future Sci OA. 2018;4: FSO323.

15 Abedin T, Al Mamun M, Lasker MAA, et al. Social media as a platform for information about diabetes foot care: a study of Facebook groups. Can J Diabetes. 2017;41, 97-1.

16 Petrovski G, Zivkovic M, Stratrova SS. Social media and diabetes: can Facebook and Skype improve glucose control in patients with type 1 diabetes on pump therapy? One-year experience. Diabetes Care. 2015;38:e51-e52. 